\title{
Community engagement in an international sailing event: the Monsoon Cup in Malaysia
}

\begin{abstract}
Purpose: The aim of this study was to explore resident perceptions of, and engagement with a staged sport event, the Monsoon Cup. The Monsoon Cup is an international yachting regatta which is held annually in Terengganu, Malaysia and is strongly supported by their Federal Government to raise the country's international profile as a popular sport tourism destination. Previous studies have reviewed residents' attitudes towards tourism development and the factors that influence their perceptions. However, little research has been conducted on residents' expectations, interests and needs in terms of a specific mega sport tourism event such as the Monsoon Cup.
\end{abstract}

Design/methodology/approach: A qualitative methodology using semi-structured interviews was the principal means of collecting data. The sample consisted of local residents living in Pulau Duyong, five kilometers from the capital of Terengganu. Thirty-six residents were interviewed with the majority being male $(N=28)$, with ages ranging from 20 to 73 years. A number of questions were developed and pilot tested before being posed to the study respondents about the annual staging of the Monsoon Cup. NVIVO 9.1 computer software package was used to code, compare and classify the major themes that recurred or were common in the data set.

Findings: The findings provided strong support for the critical importance of actively engaging local residents in the staging of such a large-scale event. In the first year of operation, many of the local residents of Pulau Duyong had enthusiastically participated in MC-related activities; however, the level of engagement had declined significantly in the recent years. In the future, every effort must be taken to focus on the development of better lines of communication and information dissemination with respect to the planning and actual staging of the annual event than is currently the case. Practical implications Community feedback suggested that key stakeholders involved in the staging of the Monsoon Cup have a critical role to play in the future in engaging local residents of Pulau Duyong more purposefully in the event itself. Greater effort must be made on the part of event organisers to actively recruit local residents to assist with the event planning, promotion and staging of the regatta. In addition, the distribution of brochures on a periodic basis to convey information about event-related activities and opportunities for community engagement were suggested to be a highly desirable first step.

Practical implications: Community feedback suggested that the event company involved in the staging of the Monsoon Cup had a critical role to play in engaging local residents of Pulau Duyong more purposefully in the event itself. In particular, effort needed to be focussed initially on the development of better lines of communication and information dissemination with respect to the planning and actual staging of the annual event than was currently the case.

Originality/value: This research will be of great benefit to the key stakeholders involved in the staging of the event, which includes local government, the event organisers, tourism 
professionals and community residents, by providing deeper insights into matters that residents expressed as being important. This will help to ensure that in the future, all stakeholders will be empowered contributors to the ongoing planning and annual staging of this international event.

Keyword: $\quad$ Community engagement; Mega event; Key stakeholders; Monsoon Cup Sailing Regatta; Sport tourism 